\title{
Ketogenic diet for epilepsy treatment
}

\section{Dieta cetogênica para o tratamento da epilepsia}

\author{
Letícia Pereira de Brito Sampaio ${ }^{1}$
}

\begin{abstract}
The ketogenic diet (KD), a high-fat, low-carbohydrate, and adequate-protein diet is an established, effective nonpharmacologic treatment option for intractable childhood epilepsy. The KD was developed in 1921 and even though it has been increasingly used worldwide in the past decade, many neurologists are not familiar with this therapeutic approach. In the past few years, alternative and more flexible KD variants have been developed to make the treatment easier and more palatable while reducing side effects and making it available to larger group of refractory epilepsy patients. This review summarizes the history of the KD and the principles and efficacy of the classic ketogenic diet, medium-chain triglyceride(s) (MCT) ketogenic diet, modified Atkins diet, and low glycemic index treatment.
\end{abstract}

Keywords: ketogenic diet; epilepsy; glycemic index.

\section{RESUMO}

A dieta cetogênica, rica em gorduras, adequada em proteínas e pobre em carboidratos é uma opção de tratamento efetiva e bem estabelecida para epilepsia de difícil controle na infância. Foi desenvolvida em 1921 e nos últimos 20 anos tem sido utilizada em diferentes países e culturas, porém ainda é desconhecida entre muitos neurologistas e outras especialidades. Recentemente, no esforço de tornar a dieta mais palatável, de fácil administração e com menos efeitos adversos, dietas cetogênicas alternativas foram criadas, possibilitando a sua administração a um maior número de pacientes. Nesta revisão abordaremos a história, príncipios e eficácia da dieta cetogênica, da dieta com triglicérides de cadeia média, da dieta modificada de Atkins e da dieta com baixos índices glicêmicos.

Palavras-chave: dieta cetogênica; epilepsia; índice glicêmico.

Despite the advances in the diagnosis and management of epilepsy in children and adults, and the introduction of new antiepileptic drug(s) (AED), approximately $30 \%$ of children who develop epilepsy still experience uncontrolled seizures or intolerable side effects from AEDs, besides having limited chronic treatment options.

The ketogenic diet (KD), a high-fat, low-carbohydrate, adequate-protein diet is an established, effective nonpharmacologic treatment for children with intractable epilepsy, which is defined as epilepsy that failed to respond to three or more AEDs. This therapeutic approach can be a reasonable option for adults who also have intractable epilepsy and who are not surgical candidates. Most often, patients referred to the $\mathrm{KD}$ have made use of five or more AEDs ${ }^{2,3}$.

The classic KD is tightly controlled, specifically calculated for each patient, and formulated using different protocols in different countries, occasionally with significant variations in its administration. The diet should be implemented in a multidisciplinary way under the supervision of a physician and dieti$\operatorname{tian}^{4}$. The side effects should be monitored and they include, in the short-term, acidosis, hypoglycemia, vomiting, obstipation, diarrhea, and gastroesophageal reflux. The long-term side effects usually occur after three months and consist of hyperlipidemia, constipation, renal calculi, growth failure, bone health, and deficits of vitamins, minerals and trace elements ${ }^{4}$.

\section{HISTORY OF THE KETOGENIC DIET}

Since the Hippocratic era (460 BC-370 BC), fasting has been recognized as a therapeutic treatment for epilepsy. Fasting was also documented in biblical times: Mark (9:29) relates the story of Jesus curing an epileptic boy. When his apostles asked him why they had not been able to cure the boy, Jesus said, "This kind can come out by nothing but prayer and fasting". Raphael's Transfiguration of Christ is the most famous painting of a person with epilepsy ${ }^{5,6}$.

The first scientific report on the value of fasting in epilepsy was published in the early $20^{\text {th }}$ century by the French physicians Guelpa and Marie, who reported that seizures

${ }^{1}$ Universidade de São Paulo, Hospital das Clínicas, Instituto da Criança, Departamento de Neurologia, São Paulo SP, Brasil.

Correpondence: Letícia Pereira de Brito Sampaio; HCFMUSP; Av Dr Enéas de Carvalho Aguiar, 647 ; 05403-000, São Paulo SP, Brasil; E-mail: Ipbs@uol.com.br Conflict of interest: There is no conflict of interest to declare.

Received 04 May 2016; Received in final form 04 June 2016; Accepted 08 June 2016. 
were less severe with fasting. Concurrently, the first account of fasting in the United States was a report by an osteopathic physician from the state of Michigan, Dr. Hugh W. Conklin. The second account included articles published by Bernarr Macfadden, a physical fitness cultist who in 1899 established his first magazine, Physical Culture with articles about sickly men and women who became healthy and strong through proper diet and exercise. He claimed that fasting for three days to three weeks could improve and cure any disease, including epilepsy ${ }^{6}$.

At that time, Dr. Conklin believed that epilepsy had its origin in the intestines and was curable. In one of his manuscripts, Dr. Conklin recommended a fast lasting 18-25 days or as long as the person was physically able to tolerate without eating. He reported cure rates of $90 \%$ in children younger than 10 years of age, $80 \%$ in adolescents aged $10-15$ years old, $65 \%$ in $15-25$-year-old patients, $50 \%$ in $25-40$-year-old patients, but low rates in patients 40 years and older. In 1922, Dr. A. Goldbloom, from Montreal, was more skeptical and reported "the starvation treatment is effective only while it is continued and while the patient remains in bed, but it has no enduring qualities". In 1921, another pioneer in epilepsy studies, Dr. H. Rawle Geyelin, reported his experience with fasting as a treatment of epilepsy at the American Medical Association Convention and was the first to document the cognitive improvement that could occur with fasting. In 1922, Dr. W.G. Lennox and Dr. Stanley Cobb began studying why starvation worked as a treatment for epilepsy and were the first to note an increase in serum uric acid and acidosis that typically developed after two or three days and was accompanied by a decrease in seizures. The efficacy of fasting triggered clinical and research activity and various theories arose to explain the success of starvation; dehydration, ketosis and acidosis were all considered potential mechanisms to explain the efficacy of fasting ${ }^{4}$.

At about the same time, in 1921, Dr. R.T. Woodyatt noted that normal subjects under starvation or on diets containing extremely low carbohydrate proportions and extremely high fat proportions would produce acetone and beta-hydroxybutyric acid ${ }^{7}$. Dr. R.M. Wilder, a physician at the Mayo Clinic (Rochester, United States), proposed that the benefits of fasting could be obtained if ketonemia was produced by other means and coined the term "ketogenic diet", which referred to diets rich in fat and low in carbohydrate. He proposed that the $\mathrm{KD}$ should be tried in a series of patients with epilepsy and suggested that it should be as effective as fasting and could be maintained for a much longer period of time ${ }^{8}$. Subsequently, in 1925, Dr. M.G. Peterman, also from the Mayo Clinic, proposed a KD calculation similar to the one used today: $1 \mathrm{~g}$ of protein per kilogram of body weight in children, 10-15 g of carbohydrates per day, and the remainder of the calories in fat 9 .

The KD was widely used throughout the 1920s and 1930s. When diphenylhydantoin was discovered in 1938, the attention of physicians and researchers shifted to new AEDs. Medications were easier to administer and the KD was considered difficult, rigid, expensive, and therefore was scarcely used. As time went by, even physicians and dietitians forgot about this treatment and only a few centers continued to offer the $\mathrm{KD}^{4}$.

In an effort to make the classic $\mathrm{KD}$ more palatable, Huttenlocher et al., introduced a medium-chain triglyceride (MCT) oil diet that was more ketogenic per calorie, allowing less restriction of carbohydrates and protein ${ }^{10}$.

In 1994, the KD received national media attention in the United States when the NBC TV network aired a program based on the true story of Charlie, a two-year-old boy with intractable epilepsy. Charlies father, Jim Abrahams, found a reference to the $\mathrm{KD}$ while researching treatments for epilepsy on his own and brought his son to Johns Hopkins Hospital, in Baltimore, which was the only epilepsy center in the United States that had continued to offer the KD, at the discretion of Dr. Freeman and Ms. Millicent Kelly, an experienced dietitian, for diet initiation. Charlie became seizure-free and showed developmental progress ${ }^{4}$. Jim Abrahams created the Charlie Foundation to spread information about the KD and made videos for parents about the diet, as well as one for physicians and dietitians, provided funds for publications, and supported the first multicenter prospective study on the efficacy of the $\mathrm{KD}^{11}$. In 1997, Jim Abrahams directed the film "First Do No Harm”, starring Meryl Streep, about Charlie's fight against epilepsy. In 2004, Emma Williams started the Matthew's Friends Charity in honor of her son to provide support for dietary treatments for epilepsy.

Since then, there has been a dramatic increase in the number of scientific articles about the $\mathrm{KD}$ and clinical studies have established the diet as an effective treatment for epilepsy. The KD is now available in over 45 countries. Additionally, new $\mathrm{KD}$ variants are in use, such as the modified Atkins diet (MAD) and the low glycemic index diet, with ketogenic formulas also being available ${ }^{12}$.

The Atkins diet was promoted in 1972 by the cardiologist Dr. Robert C. Atkins. The diet is high in fat, low in carbohydrates, and produces ketosis. The MAD was first introduced in 2003 at Johns Hopkins, following up on a report of a mother who had started her child on the Atkins diet by herself while she was waiting for the $\mathrm{KD}$ initiation and discovered that the child's seizures were controlled. This alternative diet induces ketosis in a more palatable and less restrictive manner. In the modified Atkins diet, patients limit their daily intake of net carbohydrates to $10-20 \mathrm{~g} /$ day indefinitely. The $\mathrm{MAD}$ is also being increasingly used for adults due to its better practicality and tolerability ${ }^{4,13}$.

The use of the low glycemic index treatment (LGIT) in treating epilepsy was first reported in $2005^{14}$. The hypothesis is that stabilization of blood glucose levels may be one of the mechanisms of action of this $\mathrm{KD}$ variant, which would also result in modulation of insulin secretion and other 
metabolic effects. The first cases for LGIT were two adolescent boys with refractory epilepsy who experienced a greater than $90 \%$ reduction in seizure frequency after administration of the classic KD. However, neither boy tolerated the restrictiveness of the KD. After the KD was discontinued, the parents of one boy noted a fluctuation in seizure frequency based on carbohydrate intake, with an increase in seizure frequency when high carbohydrate foods were consumed. Following this observation, both boys were started on a diet that permitted higher total carbohydrate intake than the classic $\mathrm{KD}$, but with the carbohydrates limited to "low glycemic index" foods that produce relatively little elevation in blood glucose; both experienced $>90 \%$ seizure reduction.

\section{MECHANISM OF ACTION}

The underlying mechanism of the $\mathrm{KD}$ action remains unclear and research in animal models of epilepsy suggest that the mechanism of action is much more complicated than that which has been already reported, and involves alterations in mitochondrial function, effects of ketone bodies on neuronal function and neurotransmitter release, antiepileptic effects of fatty acids, and/or glucose stabilization. Ketone bodies may increase membrane potential hyperpolarization and $\bigotimes$-aminobutyric acid synthesis, and decrease release of glutamate, norepinephrine, or adenosine. The $\mathrm{KD}$ may also play a role in the inhibition of the mammalian target of rapamycin (mTOR) $)^{15,16,17}$.

\section{CLASSIC KETOGENIC DIET}

The classic KD is calculated in a ratio of grams of fat to grams of carbohydrate plus protein. The most common ratio is $3: 1$ or $4: 1$, which means that $90 \%$ of the energy comes from fat and $10 \%$ from carbohydrate and protein combined. Calories are typically restricted to $80-90 \%$ of the daily recommendations for age. Fluid restriction to $90 \%$ is based on historical use of the diet rather than on scientific evidence ${ }^{18}$.

In 1998, with support of the Charlie Foundation, a multicenter study was conducted with 51 children who averaged 230 seizures/month before starting the diet. Approximately half $(47 \%)$ of the children remained on the diet for one year and $43 \%$ of those experienced $>90 \%$ seizure control and were almost seizure-free; $39 \%$ had 50-90\% seizure control and $17 \%$ were non-responders with less than 50\% seizure control. Adverse events that were attributed to the KD included lethargy, severe dehydration or acidosis, mood changes, increased infections, constipation, and vomiting. The reasons for discontinuation were intolerance, difficulty of maintaining the restrictive diet, and inadequate seizure control. The authors believed that the reduction in seizures was unlikely to be a placebo effect ${ }^{11}$. In the same year, the $\mathrm{KD}$ group at Johns
Hopkins published a study of 150 children aged between one to 16 years, who averaged 410 seizures/month before the diet. One year after KD initiation, $27 \%$ of children had $>90 \%$ reduction in seizure frequency, $7 \%$ were seizure-free, and $50 \%$ had $>50 \%$ reduction in the seizure frequency. The authors also observed that children who had success with the KD had $>50 \%$ reduction in seizure frequency during the first three months and that reduction could improve gradually, but if a $50 \%$ reduction was not observed during that time, it was unlikely to occur in subsequent months ${ }^{19,20}$.

Seventy children with refractory epilepsy were enrolled in a retrospective long-term follow-up study at the Children's Institute of the University of São Paulo (USP), São Paulo, Brazil to evaluate the efficacy and tolerability of the KD. At one year, $55 \%$ of those who were initiated on the diet remained on the $\mathrm{KD}$ and $70 \%$ had $>75 \%$ seizure control, $25 \%$ had $50-75 \%$ seizure control, and $2.5 \%$ had $<50 \%$ seizure control. The $\mathrm{KD}$ efficacy was significantly higher for generalized epilepsy than for partial epilepsy ( $\mathrm{p}<0.001)$. Approximately $10 \%$ of children discontinued the diet because of its unpalatability and $3.7 \%$ experienced nausea and vomiting ${ }^{21}$.

In 2008, Neal et al. ${ }^{22}$ conducted the first randomized controlled trial to assess the efficacy of the KD. The authors followed 145 children with epilepsy who were unresponsive to two AEDs and who had at least seven seizures/week. Children were randomized into two groups: one received the KD immediately (KD group) and the other after three months with AEDs in a stable dose (control group). After three months, the KD group experienced a $75 \%$ reduction in seizure frequency compared to controls. Additionally, $38 \%$ of children in the KD group had $>50 \%$ seizure reduction and $7 \%$ had $>90 \%$ reduction in seizure frequency. The results clearly showed that the KD has benefits compared to no change in treatment. Nearly $25 \%$ of children who were on the $\mathrm{KD}$ reported side effects such as vomiting, lack of energy, hunger, diarrhea, abdominal pain, or taste problems. Constipation was the most reported side effect.

The KD also could be a reasonable option for adults with intractable epilepsy, providing a quick, reversible alternative to vagus nerve or deep brain stimulation. In a meta-analysis published in 2011, 270 patients were evaluated, of whom 168 received the classic $\mathrm{KD}, 87$ were on $\mathrm{MAD}$, and 15 patients used both MCT and classic KD diets. The efficacy rates of the $\mathrm{KD}$ in adult intractable epilepsy ranged from 13 to $70 \%$. The meta-analysis yielded a combined efficacy rate of the $\mathrm{KD}$ of $42 \%$, with significant heterogeneity across studies. After excluding one study dating back 80 years, this meta-analysis revealed a combined rate of patient compliance with the $\mathrm{KD}$ of $45 \%$, which was caused mainly by ineffectiveness or lack of compliance. A comparison between the classic $\mathrm{KD}$ and the $\mathrm{MAD}$ revealed that the combined efficacy rate was significantly better for the classic $\mathrm{KD}(52 \%)$ than for the MAD (34\%, $\mathrm{p}=0.036$ ), whereas the combined compliance rate was significantly higher for the MAD ( $56 \%$ vs. $38 \%, p=0.006)^{23}$. The results 
indicated that the $\mathrm{KD}$ could be a promising complementary therapy in adult intractable epilepsy and should be initiated with the MAD, with a switch to the classic $\mathrm{KD}$ being considered if greater seizure control is required. Case-control studies in adults are needed to confirm this conclusion.

The KD has been used as a "last treatment option" in patients with intractable epilepsy. Following the recommendations of the International Ketogenic Diet Study Group, the therapy should be offered earlier to a child after two AEDs are used unsuccessfully. Moreover, the $\mathrm{KD}$ is the treatment of choice for GLUT1 deficiency syndrome and pyruvate dehydrogenase deficiency. In both disorders, the $\mathrm{KD}$ provides ketones that bypass the metabolic defect and serve as an alternative fuel to the brain ${ }^{18}$. In addition, there are specific conditions in which the consensus group considered that the KD could be used earlier. In myoclonic epilepsies, including myoclonic epilepsy of infancy (Dravet Syndrome) and particularly myoclonic-atonic epilepsy (Doose Syndrome), the KD appears to be effective in leading to seizure freedom and perhaps should be considered earlier in the treatment course ${ }^{24,25}$.

The KD can also be a good option for treatment of infantile spasms. In 2008, results from a retrospective case-control study comparing the $\mathrm{KD}$ with adrenocorticotropic hormone (ACTH) for treatment of new-onset infantile spasms at Johns Hopkins Hospital showed that the KD stopped spasms in nearly two-thirds of cases, and had fewer side effects and relapses than ACTH. However, ACTH normalized the electroencephalogram more rapidly ${ }^{26}$.

Pires et al. ${ }^{27}$ evaluated the efficacy of the $\mathrm{KD}$ to treat infantile spasms as a third-line treatment, after vigabatrin and steroids. After one month, 35\% of patients were seizure-free, and $65 \%$ were seizure-free after the third month. However, after one month, an additional AED was given to non-seizure-free patients. The efficacy of the $\mathrm{KD}$ remained stable from three to six months and the diet was not stopped because of tolerability.

Because compliance is not a problem, the KD may also be an excellent option in enterally-fed children, especially with the use of ketogenic formulas, which are also easy to prepare. Additionally, the adverse effects of AEDs can be avoided.

The $\mathrm{KD}$ is contraindicated in specific disorders and, before initiating the $\mathrm{KD}$, the patient must be screened for disorders of fatty acid transport and oxidation. The presence of clinical features such as developmental delay, cardiomyopathy, hypotonia, exercise intolerance, myoglobinuria, and easy fatigability suggest that the child should be tested to rule out an inborn error of metabolism before $\mathrm{KD}$ initiation ${ }^{18}$.

The KD can be initiated in the hospital or in an outpatient setting, with or without fasting. During hospitalization, parents can receive guidance and attend lessons about the $\mathrm{KD}$, and the patient can be closely monitored for any adverse effects that may occur during this phase. Fasting accelerates diet initiation and the development of ketosis. Brief fasting is used in some centers as a way of quickly boosting ketones and improving seizure control during breakthrough seizure clusters in children on $\mathrm{KD}$.

In a randomized prospective clinical trial of children with intractable epilepsy, Bergqvist et al. compared the efficacy of fasting and gradual KD initiation protocols, measured by seizure reduction. The results showed that gradual $\mathrm{KD}$ initiation maintained seizure control efficacy, resulted in similar levels of ketosis, had lower/milder side effects, and was better tolerated overall. The gradual initiation approach may simplify the KD management for the care team, making the $\mathrm{KD}$ more available to the population in general $^{28}$.

\section{MEDIUM-CHAIN TRIGLYCERIDE (MCT) DIET}

The MCT diet was developed to make the KD more palatable, allowing for a diet with a greater proportion of carbohydrate and protein. Medium-chain triglycerides produce more ketones per kilocalorie of energy than the long-chain triglycerides used in the classic $\mathrm{KD}$, requiring less fat intake to produce ketosis compared to a classic KD because MCTs are more rapidly metabolized. Patients consume more varieties and quantities of food, have better growth, and require fewer micronutrients compared to the classic KD. There is also a positive effect on lipid levels with a significantly lower total cholesterol/high density lipoprotein ratios compared to the classic $\mathrm{KD}^{10,29}$. The traditional MCT diet was initially designed to deliver $60 \%$ of energy from medium-chain triglycerides. Frequent side effects include diarrhea, vomiting, bloating, and abdominal pain. To increase tolerability, a modified version was proposed using 30\% of energy from MCTs and $30 \%$ from long-chain fatty acids with the MCT percentage needing to be increased gradually ${ }^{30,31}$. Patients on valproate are not recommended to start on the MCT/KD because of reports of liver failure. The efficacy of the MCT diet is similar to that of the classic $\mathrm{KD}$. A randomized controlled trial comparing the MCT and classic versions of the $\mathrm{KD}$ indicated there were no significant differences between the two diets ${ }^{31}$. However, MCT oil is expensive and dietitians need to be trained to use MCT therapy.

\section{MODIFIED ATKINS DIET (MAD)}

The MAD has a ketogenic ratio of 0.9:1 ( fat: carbohydrates and protein), with approximately $65 \%$ of the calories derived from fat sources. In children, the net carbohydrates are initially limited to $10 \mathrm{~g} /$ day, with a planned increase to $20 \mathrm{~g} /$ day after three months. Adults are started at $15 \mathrm{~g} /$ day and that amount can be increased to 20-30 g/day after one month. All carbohydrates are allowed and can be given during the day or at one meal. The difference between the MAD and the Atkins diet is that, in the former, the limitation on carbohydrate intake is maintained indefinitely, fat is encouraged with 
the goal of increasing urinary ketones, and weight loss is not a goal ${ }^{34}$. The diet is started in an outpatient setting, fasting is not required, weighing of foods is not necessary, there is no limit on protein and fat consumption, calories and fluids are not restricted, and the time spent for counseling is reduced to $30-45 \mathrm{~min}$.

Sharma et al..$^{33}$ conducted a randomized controlled trial in 102 children and adolescents with refractory epilepsy to investigate if the MAD improves seizure control and found this $\mathrm{KD}$ variant is significantly more effective in controlling seizures compared to the continuation of AEDs alone.
The mean seizure frequency at three months from baseline was significantly less in the diet group than in controls (37.3 vs. $100 \%, p=0.003$ ) and similar to other uncontrolled studies of the MAD. The diet was well tolerated and side effects did not require discontinuation of the diet.

Kossof et al..$^{34}$ conducted a crossover study to determine the ideal starting carbohydrate limit in the MAD (10 or $20 \mathrm{~g} /$ day). At three months, they observed that seizure reduction was higher in children started on $10 \mathrm{~g} /$ day. After three months, an increase in carbohydrate consumption improved tolerability and had no negative impact on diet efficacy.

Table. Comparison of ketogenic diet therapies.

\begin{tabular}{|c|c|c|c|c|}
\hline Questions & Ketogenic Diet & $\begin{array}{l}\text { Medium-Chain } \\
\text { Triglycerides Oil Diet }\end{array}$ & $\begin{array}{c}\text { Low Glycemic Index } \\
\text { Treatment }\end{array}$ & Modified Atkins Diet \\
\hline $\begin{array}{l}\text { Is medical supervision } \\
\text { required? }\end{array}$ & Yes & Yes & Yes & Yes \\
\hline Is the diet high in fat? & Yes & Yes & Yes & Yes \\
\hline $\begin{array}{l}\text { Is the diet low in } \\
\text { carbohydrate? }\end{array}$ & Yes & Yes & Yes & Yes \\
\hline $\begin{array}{l}\text { What is the ratio of fat to } \\
\text { carbohydrate \& protein? }\end{array}$ & $4: 1,3: 1,2: 1,1: 1$ & Approximately 1:1 & Approximately 1:1 & Approximately 1:1 \\
\hline \multirow{4}{*}{$\begin{array}{l}\text { How much carbohydrate } \\
\text { is allowed on a } \\
1000 \text { calorie diet? }\end{array}$} & 8 g carb on a $4: 1$ & \multirow{4}{*}{$40-60 g$} & \multirow{4}{*}{$40-60 g$} & 10 g for one month \\
\hline & 16 g carb on a 3:1 & & & 20 g afterwards \\
\hline & 30 g carb on a $2: 1$ & & & \multirow[t]{2}{*}{$\begin{array}{l}\text { Adjusted for children vs. } \\
\text { adults }\end{array}$} \\
\hline & -60 g carb on a $1: 1$ & & & \\
\hline
\end{tabular}

\begin{tabular}{|c|c|c|c|c|}
\hline How are foods measured? & Weighed & Weighed & $\begin{array}{c}\text { Fat and carbohydrate } \\
\text { content is discriminated } \\
\text { or estimated }\end{array}$ & $\begin{array}{c}\text { Fat and carbohydrate } \\
\text { content is discriminated or } \\
\text { estimated }\end{array}$ \\
\hline Are meal plans used? & Yes & Yes & Yes & Optional \\
\hline Where is the diet initiated? & Hospital/Home & Hospital/Home & Home & Home \\
\hline Are calories controlled? & Yes & Yes & Yes & No \\
\hline $\begin{array}{l}\text { Are vitamin and mineral } \\
\text { supplements required? }\end{array}$ & Yes & Yes & Yes & Yes \\
\hline $\begin{array}{l}\text { Are liquids (fluids) } \\
\text { restricted? }\end{array}$ & No & No & No & No \\
\hline $\begin{array}{l}\text { Is a pre-diet laboratory } \\
\text { evaluation required? }\end{array}$ & Yes & Yes & Yes & Yes \\
\hline $\begin{array}{l}\text { Are there possible } \\
\text { side-effects? }\end{array}$ & Yes & Yes & Yes & Yes \\
\hline $\begin{array}{l}\text { What is the overall } \\
\text { difference in the design of } \\
\text { these diets? }\end{array}$ & $\begin{array}{l}\text { This is a personalized } \\
\text { and structured diet that } \\
\text { provides specific meal } \\
\text { plans. Foods are weighed } \\
\text { and meals should be } \\
\text { consumed in their entirety } \\
\text { for best results. The ratio } \\
\text { of this diet can be adjusted } \\
\text { to provide better seizure- } \\
\text { control or better tolerance. } \\
\text { This diet is also considered } \\
\text { a low glycemic therapy and } \\
\text { results in steady glucose } \\
\text { levels. }\end{array}$ & $\begin{array}{l}\text { This is a personalized } \\
\text { and structured } \\
\text { diet containing } \\
\text { medium-chain } \\
\text { triglycerides, which } \\
\text { are highly ketogenic. } \\
\text { This allows more } \\
\text { carbohydrate and } \\
\text { protein than the } \\
\text { classic ketogenic } \\
\text { diet. A source of } \\
\text { essential fatty acids } \\
\text { must be included on } \\
\text { this diet. }\end{array}$ & $\begin{array}{l}\text { This is personalized } \\
\text { but less structured diet } \\
\text { than the ketogenic diet. } \\
\text { It uses exchange lists } \\
\text { for planning meals and } \\
\text { emphasizes complex } \\
\text { carbohydrates. The } \\
\text { balance of low glycemic } \\
\text { carbohydrates in } \\
\text { combination with fats } \\
\text { result in steady glucose } \\
\text { levels. It is not intended } \\
\text { to promote ketosis. }\end{array}$ & $\begin{array}{c}\text { This diet focuses on } \\
\text { limiting the amount } \\
\text { of carbohydrate } \\
\text { while encouraging } \\
\text { fat consumption. } \\
\text { Carbohydrate may be } \\
\text { consumed at any time } \\
\text { during the day as long } \\
\text { as it is within limits and } \\
\text { should be consumed } \\
\text { with fat. Suggested meal } \\
\text { plans are used as a guide. } \\
\text { Protein is not limited but } \\
\text { excessive consumption is } \\
\text { discouraged. }\end{array}$ \\
\hline
\end{tabular}


The efficacy of the MAD in adults was evaluated in an open-label study and the data showed that, on average, $27 \%$ of adolescents and adults achieved $\geq 50 \%$ seizure reduction and $6 \%$ became seizure-free ${ }^{35}$. The diet was slightly more effective in those with higher initial seizure frequencies and in younger adults. The MAD can also be administered to adults with intractable epilepsy and counseling can be done by e-mail in a feasible, safe, and effective manner ${ }^{36}$.

\section{LOW GLYCEMIC INDEX TREATMENT (LGIT)}

The low glycemic index treatment (LGIT) is less restrictive than the classic $\mathrm{KD}$ because it allows consumption of low glycemic index foods, while encouraging fat intake. The glycemic index (GI) describes the tendency of foods to elevate blood glucose ${ }^{37}$. Low glycemic index foods cause a minor elevation in postprandial blood glucose and insulin levels. The LGIT allows for more carbohydrate intake, but restricts foods to those with GI $<50$. At initiation, patients and their families are instructed to exclude high-GI carbohydrates from the diet and limit total carbohydrates to 40-60 g/day. Fat and protein are encouraged. Muzykewicz et al..$^{38}$ published a retrospective study with 76 children with intractable epilepsy who were managed with the LGIT. The one year followup showed a greater than $50 \%$ seizure reduction in $66 \%$ of patients in the cohort. Coppolla et al. ${ }^{39}$ showed that the LGIT was effective in seizure control, well accepted and tolerated for prolonged periods in children and young adults. Of the 15 patients, with a median follow-up period of 12 months, $40 \%$ had $75-90 \%$ seizure reduction, $13.3 \%$ had $50 \%$ seizure reduction, and $46.7 \%$ of patients were non-responders. No adverse events occurred during the diet. The LGIT produces a lower level of ketosis than that of the classic KD. The effect of the LGIT was shown to correlate with lower serum glucose levels at some time points.

For a comparison between ketogenic diet therapies, see the Table.

\section{FINAL REMARKS}

All KD therapies offer a treatment for intractable epilepsy with confirmed efficacy.

In the past few years, alternative, more liberal $\mathrm{KD}$ variants have been developed to make the treatment easier and more palatable while reducing side effects and making it available to a larger group of refractory epilepsy patients.

Clinical evidence suggests that the efficacy of alternative diets is similar to that of the classic $\mathrm{KD}$, but a rigid and strict initiation protocol with carbohydrate limitation and increased fat intake is crucial to achieve a high efficacy.

The choice of the diet must be made on an individual basis considering the patient's age, family circumstances, and severity and type of epilepsy.

Pediatric and adult neurologists must be able to identify and refer appropriate patients to the $\mathrm{KD}$ as soon as necessary in the course of epilepsy instead of using it as a last option only.

\section{References}

1. Kwan P, Brodie MJ. Early identification of refractory epilepsy. N Engl J Med. 2000;342(5):314-9. doi:10.1056/NEJM200002033420503

2. Martin K, Jackson CF, Levy RG, Cooper PN. Ketogenic diet and other dietary treatments for epilepsy. Cochrane Database Syst Rev. 2016;2:CD001903.pub3. doi:10.1002/14651858.CD001903.pub3

3. Kessler SK, Neal EG, Camfield CS, Kossoff EH. Dietary therapies for epilepsy: future research. Epilepsy Behav. 2011;22(1):17-22. doi:10.1016/j.yebeh.2011.02.018

4. Freeman JM, Kossoff EH, Freeman JB, Kelly MT. The ketogenic diet: a treatment for children and others with epilepsy. New York: Demos Medical Publishing; 2007.

5. Cervenka MC, Kossoff EH. Dietary treatment of intractable epilepsy. Continuum (Minneap Minn). 2013;19(3 Epilepsy):756-66. doi:10.1212/01.CON.0000431396.23852.56

6. Wheless JW History of the ketogenic diet. Epilepsia. 2008;49 Suppl 8:3-5. doi:10.1111/j.1528-1167.2008.01821.x

7. Woodyatt RT. Objects and method of diet adjustment in diabetics. Arch Intern Med (Chic). 1921;28(2):125-41. doi:10.1001/ archinte.1921.00100140002001

8. Wilder RM. The effect on ketonemia on the course of epilepsy. Mayo Clin Bull. 1921;2:307-8.

9. Peterman MG. The ketogenic diet in epilepsy. JAMA. 1925;84(26):1979-83. doi:10.1001/jama.1925.02660520007003
10. Huttenlocher PR, Wilbourn AJ, Signore JM. Medium-chain triglycerides as a therapy for intractable childhood epilepsy. Neurology. 1971;21(11):1097-103. doi:10.1212/WNL.21.11.1097

11. Vining EP, Freeman JM, Ballaban-Gil K, Camfield CS, Camfield $\mathrm{PR}$, Holmes GL et al. A multicenter study of the efficacy of the ketogenic diet. Arch Neurol. 1998;55(11):1433-7. doi:10.1001/archneur.55.11.1433

12. Kossoff EH, McGrogan JR. Worldwide use of the ketogenic diet. Epilepsia. 2005;46(2):280-9. doi:10.1111/j.0013-9580.2005.42704.x

13. Chen W, Kossoff EH. Long-term follow-up of children treated with the modified Atkins diet. J Child Neurol. 2012;27(6):754-8. doi:10.1177/0883073812441062

14. Pfeifer HH, Thiele EA. Low-glycemic-index treatment: a liberalized ketogenic diet for treatment of intractable epilepsy. Neurology. 2005;65(11):1810-2. doi:10.1212/01.wnl.0000187071.24292.9e

15. Rho JM. How does the ketogenic diet induce anti-seizure effects? Neurosci Lett. 2015;26:304. doi:10.1016/j.neulet.2015.07.034

16. Lima PA, Sampaio LP, Damasceno NR. Neurobiochemical mechanisms of a ketogenic diet in refractory epilepsy. Clinics (São Paulo). 2014;69(10):699-705. doi:10.6061/clinics/2014(10)09

17. McDaniel SS, Rensing NR, Thio LL, Yamada KA, Wong $M$. The ketogenic diet inhibits the mammalian target of rapamycin (mTOR) pathway. Epilepsia. 2011;52(3):e7-11. doi:10.1111/j.1528-1167.2011.02981.x 
18. Kossoff EH, Zupec-Kania BA, Amark PE, Ballaban-Gil KR, Christina Bergqvist AG, Blackford R et al. Optimal clinical management of children receiving the ketogenic diet: recommendations of the International Ketogenic Diet Study Group. Epilepsia. 2009;50(2):304-17. doi:10.1111/j.1528-1167.2008.01765.x

19. Freeman JM, Vining EP, Pillas DJ, Pyzik PL, Casey JC, Kelly LM. The efficacy of the ketogenic diet 1998: a prospective evaluation of intervention in 150 children. Pediatrics. 1998;102(6):1358-63. doi:10.1542/peds.102.6.1358

20. Wu YJ, Zhang LM, Chai YM, Wang J, Yu LF, Li WH et al. Six-month efficacy of the Ketogenic diet is predicted after 3 months and is unrelated to clinical variables. Epilepsy Behav. 2016;55:165-9. doi:10.1016/j.yebeh.2015.12.008

21. Freitas A, Paz JA, Casella EB, Marques-Dias MJ. Ketogenic diet for the treatment of refractory epilepsy: a 10 year experience in children. Arq Neuropsiquiatr. 2007;65(2B):381-4. doi:10.1590/S0004-282X2007000300003

22. Neal EG, Chaffe H, Schwartz RH, Lawson MS, Edwards N, Fitzsimmons $\mathrm{G}$ et al. The ketogenic diet for the treatment of childhood epilepsy: a randomised controlled trial. Lancet Neurol. 2008;7(6):500-6. doi:10.1016/S1474-4422(08)70092-9

23. Ye F, Li XJ, Jiang WL, Sun HB, Liu J. Efficacy of and patient compliance with a ketogenic diet in adults with intractable epilepsy: a meta-analysis. J Clin Neurol. 2015;11(1):26-31. doi:10.3988/jcn.2015.11.1.26

24. Laux L, Blackford R. The ketogenic diet in Dravet syndrome. J Child Neurol. 2013;28(8):1041-4. doi:10.1177/0883073813487599

25. Kelley SA, Kossoff EH. Doose syndrome (myoclonic-astatic epilepsy): 40 years of progress. Dev Med Child Neurol. 2010;52(11):988-93. doi:10.1111/j.1469-8749.2010.03744.x

26. Kossoff EH, Hedderick EF, Turner Z, Freeman JM. A casecontrol evaluation of the ketogenic diet versus ACTH for new-onset infantile spasms. Epilepsia. 2008;49(9):1504-9. doi:10.1111/j.1528-1167.2008.01606.x

27. Pires ME, Ilea A, Bourel E, Bellavoine V, Merdariu D, Berquin $P$ et al. Ketogenic diet for infantile spasms refractory to firstline treatments: an open prospective study. Epilepsy Res. 2013;105(1-2):189-94. doi:10.1016/j.eplepsyres.2012.11.009

28. Bergqvist AG, Schall JI, Gallagher PR, Cnaan A, Stallings VA. Fasting versus gradual initiation of the ketogenic diet: a prospective, randomized clinical trial of efficacy. Epilepsia. 2005;46(11):1810-9. doi:10.1111/j.1528-1167.2005.00282.x
29. Liu YM. Medium-chain triglyceride (MCT) ketogenic therapy. Epilepsia. 2008;49 Suppl 8:33-6. doi:10.1111/j.1528-1167.2008.01830.x

30. Schwartz RH, Eaton J, Bower BD, Aynsley-Green A. Ketogenic diets in the treatment of epilepsy: short-term clinical effects. Dev Med Child Neurol.; 1989; 31(2):145-51. doi:10.1111/j.1469-8749.1989.tb03972.x

31. Neal EG, Chaffe H, Schwartz RH, Lawson MS, Edwards N, Fitzsimmons $\mathrm{G}$ et al. A randomized trial of classical and medium-chain triglyceride ketogenic diets in the treatment of childhood epilepsy. Epilepsia. 2009;50(5):1109-17. doi:10.1111/j.1528-1167.2008.01870.x

32. Kossoff EH, Dorward JL. The modified Atkins diet. Epilepsia. 2008;49 Suppl 8:37-41. doi:10.1111/j.1528-1167.2008.01831.x

33. Sharma S, Sankhyan N, Gulati S, Agarwala A. Use of the modified Atkins diet for treatment of refractory childhood epilepsy: a randomized controlled trial. Epilepsia. 2013;54(3):481-6. doi:10.1111/epi.12069

34. Kossoff EH, Turner Z, Bluml RM, Pyzik PL, Vining EP. A randomized, crossover comparison of daily carbohydrate limits using the modified Atkins diet. Epilepsy Behav. 2007;10(3):432-6. doi:10.1016/j.yebeh.2007.01.012

35. Payne NE, Cross JH, Sander JW, Sisodiya SM. Theketogenic and related diets in adolescents and adults: a review. Epilepsia. 2011;52(11):1941-8. doi:10.1111/j.1528-1167.2011.03287.x

36. Cervenka MC, Terao NN, Bosarge JL, Henry BJ, Klees AA, Morrison PF et al. E-mail management of the modified Atkins Diet for adults with epilepsy is feasible and effective. Epilepsia. 2012;53(4):728-32. doi:10.1111/j.1528-1167.2012.03406.x

37. Jenkins DJ, Wolever TM, Taylor RH, Barker H, Fielden H, Baldwin JM et al. Glycemic index of foods: a physiological basis for carbohydrate exchange. Am J Clin Nutr. 1981;34(3):362-6.

38. Muzykewicz DA, Lyczkowski DA, Memon N, Conant KD, Pfeifer HH, Thiele EA. Efficacy, safety, and tolerability of the low glycemic index treatment in pediatric epilepsy. Epilepsia. 2009;50(5):1118-26. doi:10.1111/j.1528-1167.2008.01959.x

39. Coppola G, D’Aniello A, Messana T, Di Pasquale F, della Corte R, Pascotto A et al. Low glycemic index diet in children and young adults with refractory epilepsy: first Italian experience. Seizure. 2011;20(7):526-8. doi:10.1016/j.seizure.2011.03.008

40. Charlie Foundation for Ketoghenic Therapies. Explore ketogenic diets. What is the ketogenic diet? Introducing the diet. Santa Monica: Charlie Foundation for Ketoghenic Therapies; 2016 [cited 2016 May 16]. Available from: http://www.charliefoundation. org/explore-ketogenic-diet/explore-1/introducing-the-diet 